\title{
Adsorption Studies of Silica Adsorbent Using Rice Husk as a Base Material for Metal Ions Removal from Aqueous Solution
}

\author{
Rose Erdoo Kukwa ${ }^{1, ~ *}$, Donald Tyoker Kukwa ${ }^{2}$, Ahola David Oklo ${ }^{1}$, Terungwa Thaddeus Ligom ${ }^{1}$, \\ Benjamin Ishwah ${ }^{1}$, John Ajegi Omenka ${ }^{3}$ \\ ${ }^{1}$ Department of Chemistry, Faculty of Science, Benue State University, Makurdi, Nigeria \\ ${ }^{2}$ Department of Engineering and the Built Environment, Durban University of Technology, Durban, South Africa \\ ${ }^{3}$ College of Education Oju, Oju, Benue State, Nigeria
}

Email address:

Erdoo.rose@gmail.com (R. E. Kukwa), tyokerdoo@gmail.com (D. T. Kukwa), oklodahalo@gmail.com (A. D. Oklo), ligomthaddeus@gmail.com (T. T. Ligom), ishwahlizer@gmail.com (B. Ishwah), Omenkaajegi83@gmail.com (J.A. Omenka)

${ }^{*}$ Corresponding author

\section{To cite this article:}

Rose Erdoo Kukwa, Donald Tyoker Kukwa, Ahola David Oklo, Terungwa Thaddeus Ligom, Benjamin Ishwah, John Ajegi Omenka. Adsorption Studies of Silica Adsorbent Using Rice Husk as a Base Material for Metal Ions Removal from Aqueous Solution. American Journal of Chemical Engineering. Vol. 8, No. 2, 2020, pp. 48-53. doi: 10.11648/j.ajche.20200802.12

Received: March 18, 2020; Accepted: April 8, 2020; Published: April 28, 2020

\begin{abstract}
This study was carried out to evaluate the efficiency of metal ions removal from aqueous solution using silica adsorbent. Silica was extracted from rice husk using sol-gel method. The silica was modified with $1.0 \mathrm{M}$ of nitric acid. Using batch adsorption technique, the effects of temperature, $\mathrm{pH}$, contact time and adsorbent dosage on adsorption process of $\mathrm{Cu}$ (II), $\mathrm{Zn}$ (II), Mn (II) and $\mathrm{Pb}$ (II) ions were studied using standard solutions of their salts. Percentage removal of the metals ions studied decreased as the temperature was varied between $28^{\circ} \mathrm{C}$ and $43^{\circ} \mathrm{C}$. Percentage removal of metal ions studied showed an increase at different $\mathrm{pH}$ varying from 4 to 8 and decreased after the $\mathrm{pH} 8$. The variation of contact time between 2 and 8 hours showed a sharp increase in metals removal from 2 to 6 hours but a slow increase after 6 hours. The percentage removal of metal ions increase as the adsorbent dosage increased between $0.5 \mathrm{~g}$ and $2.0 \mathrm{~g}$. The maximum percentage removal of metal ions was found to be $99.48 \%$. The general observed trend of efficiency being $\mathrm{Cu}>\mathrm{Pb}>\mathrm{Zn}>\mathrm{Mn}$. The experimental data was also tested using adsorption isotherm models of Langmuir and Freundlich and Langmuir model was found to be the best fit for the data.
\end{abstract}

Keywords: Adsorption, Silica, Adsorbent, Rice Husk and Aqueous Solution

\section{Introduction}

Rice husk, an outer cover of rice grain, is a by-product of the rice milling industry. It is a crop residue with uniform size and high content of ash $(18 \%-25 \%)$. The silica content of the rice husk ash (RHA) can be as high as $85-95 \%$ [1]. The type of ash varies considerably depending on the techniques employed for calcination. The silica in the ash undergoes structural transformation depending on the temperature during combustion. At $600{ }^{\circ} \mathrm{C}$, an amorphous silica is formed, at $700{ }^{\circ} \mathrm{C}$, there is a transition region from amorphous to crystalline silica, while at $800{ }^{\circ} \mathrm{C}$ above till the melting point of the ash, only the crystalline silica is formed [2].

Silica is a substance that is composed of one atom of silicon and two atoms of oxygen which is also known as silicon dioxide $\left(\mathrm{SiO}_{2}\right)$ [3]. This silica finds wide relevance as filler, adsorbent, catalyst support and star gels. Various metal ions and unburned carbon impact the pureness and colour of the ash. Under specific condition prescribed burning of the husk after removing these ions can produce high purity white silica [4].

Silica has gained major significance and various applications in different industries such as rubber, pharmaceuticals and medicine. The smoke generated because 
of burning often has unfavorable consequences on domestic as well as international environmental problems [4].

Considerable attention has been given in recent years to modify catalytic surfaces, making it more efficient for reactions [5]. Alternatives to conventional heterogeneous catalyst are possible by such chemical modifications of the silica as an adsorbent obtained from rice husk.

An adsorbent is a substance that attracts other materials or particles to its surface. There are various types of adsorbent which include; molecular sieves, activated carbon silica gel, activated alumina, clay, etc. These adsorbents have applications in petroleum refining, gas refining, chemicals/petrochemicals, water treatment, air separation and drying and packaging [5]. An adsorbent which can be prepared cheaply may be considered as a low-cost adsorbent. There are some low-cost adsorbents that have been utilised for the removal of heavy metal ions such as fly ash pellet, dried activated sludge, Cashew nut shells and bagasse fly ash [6].

The tremendous increase in the use of heavy metals for industrial activities over the few decades has inevitably resulted in an increased influx of heavy metallic contaminations into the environment. These metals are of special concern because of their persistence in the environment and the danger they pose to man's health and its environment. Examples of heavy metals include lead, arsenic, cadmium, chromium, copper, zinc, mercury, iron, aluminium, nickel, barium, manganese, beryllium etc [7].

There are various methods of removing heavy metal ions, and they include chemical precipitation, membrane process, ion exchange, solvent extraction, electrodialysis, and reverse osmosis. These methods are non-economical and have many disadvantages such as incomplete metal removal, high reagent and energy consumption, and generation of toxic sludge or other waste products that require disposal or treatment [8].

Biosorption is a process that utilizes low-cost biosorbent to sequester toxic heavy metals. Biosorption has distinct advantages over the conventional methods, which include reusability of biomaterial, low operating cost, selectivity for specific metal, short operation time and no chemical sludge [9]. In the recent years many biosorbent materials of agricultural based have been utilied for heavy metal biosorption. These include coconut husk and shell, sea weeds, bagasse ash, hazelnut shell, peanut hull, tree fern, black gram husk, maize leaf, maize fibre, sun flower waste, coffee beans, Ficus religiosa leaves, wheat bran, almond shell, tea waste [9].

According to the Encyclopaedia Britannica (2013), adsorption is a capability of all solid substances to attract to their surfaces molecules of gaseous or solutions with which they are in contact [10]. This process creates a film of the adsorbate (the molecules or atoms being accumulated) on the surface of the adsorbent. It differs from absorption, in which a fluid permeate or is dissolved by a liquid or solid [11]. The term sorption encompasses both processes, while desorption is the reverse of adsorption. Similar to surface tension, adsorption is a consequence of surface energy. In a bulk material, all the bonding requirement (be they ionic, covalent, or metallic) of the constituent atoms of the material are filled by other atoms in the material. However, atoms on the surface of the adsorbent are not wholly surrounded by other adsorbent atoms and therefore can attract adsorbates. The exact nature of the bonding depends on the details of the species involved, but the adsorption process is generally classified as physisorption (characteristics of weak van der Waals forces) or chemisorption (characteristic of covalent bonding). It may also occur due to electrostatic attraction [11].

\section{Materials and Methods}

\subsection{Sample Collection and Pretreatment}

Rice husk was obtained from Rice mill in Wurukum, New Bridge Road, Makurdi, Makurdi Local Governemnt Area of Benue State. Rice husk obtained after sieving was washed with distilled water to remove dust and dried at room temperature for $48 \mathrm{~h}$ [5].

\subsection{Extraction of Silica from Rice Husk}

The rice husk obtained in 3.1 above was ashed using a muffle furnace at $600^{\circ} \mathrm{C}$ for $4 \mathrm{~h}$ and cooled to room temperature. The rice husk ash was then treated with $200 \mathrm{~mL}$ portions of $1 \mathrm{M} \mathrm{NaOH}$ and heated at $80^{\circ} \mathrm{C}$ in $250 \mathrm{~mL}$ Erlenmeyer flasks for $1 \mathrm{~h}$ with constant stirring. The solution was allowed to cool to room temperature and filtered through Whatman filter paper $(110 \mathrm{~mm})$, the residue was washed with $100 \mathrm{~mL}$ of distilled water. The filtrate was treated with $1 \mathrm{M}$ $\mathrm{HCl}$ with constant stirring to $\mathrm{pH} 7$. Silica gel precipitated when the $\mathrm{pH}$ was less than 10 . The silica gel obtained was aged for $24 \mathrm{~h}$. The gel was transferred into a beaker and dried at $80^{\circ} \mathrm{C}$ for $12 \mathrm{~h}$ to produce xerogels. Silica xerogel sample was ground and washed with distilled water. The sample was stored in airtight plastic bottles for further analysis [12]. The equations of the reactions are as follows.

$$
\begin{gathered}
\mathrm{SiO}_{2}+2 \mathrm{NaOH} \rightarrow \mathrm{Na}_{2} \mathrm{SiO}_{3}+\mathrm{H}_{2} \mathrm{O} \\
\mathrm{Na}_{2} \mathrm{SiO}_{3}+2 \mathrm{HCl} \rightarrow \mathrm{SiO}_{2}+2 \mathrm{NaCl}+\mathrm{H}_{2} \mathrm{O}
\end{gathered}
$$

\subsection{Aqueous Solution of Heavy Metals}

Various grams of metals ions $\left(\mathrm{Pb}^{2+}, \mathrm{Cu}^{2+}, \mathrm{Mn}^{2+}, \mathrm{Zn}^{2+}\right)$ $1000 \mathrm{mg} / \mathrm{L} \mathrm{3}, 2,2.5$, and 1.5 for $\mathrm{Pb}\left(\mathrm{NO}_{3}\right)_{2}, \mathrm{CuSO}_{4}, \mathrm{MnSO}_{4}$, $\mathrm{ZnSO}_{4}$ were weighed with a weighing balance and prepared from their salts as stock solutions. The standard solutions of the metal ions $100 \mathrm{mg} / \mathrm{L}$ were then prepared from the stock solutions [13].

\subsection{Adsorption Experiment}

Batch adsorption experiments were carried out to study the percentage adsorbed and equilibrium capacity of the modified silica and also the effect of contact time, dosage, temperature and $\mathrm{pH}$ on the adsorption of $\mathrm{Pb}^{2+}, \mathrm{Cu}^{2+}, \mathrm{Mn}^{2+}$, $\mathrm{Zn}^{2+}$. 
The efficiency of the modified adsorbent for all the metals was calculated as adsorption percentages using the equation,

$$
\text { Adsorption }(\%)=\frac{C_{i-C_{f}}}{C_{i}} \times 100
$$

where $C_{i}$ and $C_{f}$ are the initial and final metal ion concentrations respectively,

The equilibrium capacity of adsorption is calculated using the formula below;

$$
\mathrm{q}_{\mathrm{e}}=\left(\mathrm{C}_{\mathrm{o}}-\mathrm{C}_{\mathrm{e}}\right) \times \frac{V}{M}
$$

where $\mathrm{q}_{\mathrm{e}}(\mathrm{mg} / \mathrm{g})$ is the equilibrium adsorption capacity, $\mathrm{C}_{\mathrm{o}}$ $(\mathrm{mg} / \mathrm{L})$ and $\mathrm{C}_{\mathrm{e}}(\mathrm{mg} / \mathrm{L})$ is the initial and equilibrium metal concentration, respectively, $\mathrm{V}$ is the volume $(\mathrm{L})$ and $(\mathrm{M})$ is the amount of the adsorbent [14].

\section{Results and Disccusion}

The results of the effect of temperature, $\mathrm{pH}$, contact time and adsorbent dosage are presented in Tables 1, 2, 3 and 4 respectively. Tables 5 and 6 show the values of the Langmuir and Freudlich adsorption isotherm, respectively.

Table 1. Effect of temperature on metal ions removal by modidified silica.

\begin{tabular}{lllll}
\hline \multirow{2}{*}{ Temperature $\left({ }^{\circ} \mathbf{C}\right)$} & Metal ion adsorbed (\%) & & Pb & \\
\cline { 2 - 5 } & $\mathbf{C u}$ & Mn & 96.60 & \\
\hline 28 & 91.46 & 92.02 & 94.57 & 93.53 \\
33 & 88.91 & 89.97 & 92.03 & 88.80 \\
38 & 82.96 & 86.98 & 91.35 \\
43 & 79.89 & 83.92 & 87.81 & 86.78 \\
\hline
\end{tabular}

Table 2. Effect of $p H$ on metal ions removal by modified silica.

\begin{tabular}{lllll}
\hline \multirow{2}{*}{ Ph } & Metal ion adsorbed (\%) & & Pb & \\
\cline { 2 - 5 } & Cu & Mn & 98.34 & \\
\hline 4 & 92.36 & 87.54 & 99.28 & 90.78 \\
6 & 97.93 & 90.15 & 99.48 & 95.11 \\
8 & 99.33 & 96.95 & 96.72 & 88.62 \\
10 & 89.05 & 82.13 & 9.82 \\
\hline
\end{tabular}

Table 3. Effect of contact time on metal ions removal by modified silica.

\begin{tabular}{lllll}
\hline \multirow{2}{*}{ Time (Hour) } & \multicolumn{2}{l}{ Metal ion percentage adsorbed (\%) } & Pb & \\
\cline { 2 - 5 } & Cu & Mn & 98.83 & \\
\hline 2 & 89.07 & 80.91 & 98.94 & 98.10 \\
3 & 90.14 & 81.09 & 99.04 & 98.21 \\
4 & 90.20 & 81.48 & 99.09 & 98.33 \\
5 & 94.43 & 81.69 & 99.20 & 98.44 \\
6 & 94.67 & 82.18 & 99.23 & 98.56 \\
7 & 94.68 & 82.19 & 99.27 \\
\hline
\end{tabular}

Table 4. Effect of adsorbent dosage on metal ions removal by modified silica.

\begin{tabular}{lllll}
\hline \multirow{2}{*}{ Adsorbent dosage (g) } & \multicolumn{4}{l}{ Metal ion percentage adsorbed (\%) } \\
\cline { 2 - 5 } & $\mathbf{C u}$ & $\mathbf{M n}$ & $\mathbf{P b}$ & \\
\hline 0.5 & 77.67 & 84.44 & 92.34 & \\
1.0 & 83.61 & 88.99 & 96.36 & 94.72 \\
1.5 & 86.63 & 93.07 & 97.94 & 94.93 \\
2.0 & 88.94 & 95.45 & 98.93 & 96.93 \\
\hline
\end{tabular}

Table 5. Langmuir Adsorption Isotherm.

\begin{tabular}{lllll}
\hline Metal Ion & $\mathbf{Q}_{\mathbf{m}}(\mathbf{m g} / \mathbf{g})$ & $\mathbf{K}_{\mathbf{L}}(\mathbf{m g} / \mathbf{L})$ & $\mathbf{R}_{\mathbf{L}}$ & \\
\hline $\mathrm{Cu}$ & 19.61 & 0.009 & 0.262 & $\mathbf{R}^{\mathbf{2}}$ \\
$\mathrm{Mn}$ & 14.71 & 0.017 & 0.167 & 0.998 \\
$\mathrm{~Pb}$ & 23.26 & 0.121 & 0.038 & 0.952 \\
$\mathrm{Zn}$ & 4.81 & 0.069 & 0.062 & 0.924 \\
\hline
\end{tabular}

Table 6. Freundlich Adsorption Isotherm.

\begin{tabular}{lllll}
\hline Metal Ion & $\mathbf{K}_{\mathbf{F}}(\mathbf{m g} / \mathbf{g})$ & $\frac{\mathbf{1}}{\mathbf{n}}$ & $\mathbf{N}$ & \\
\hline $\mathrm{Cu}$ & 54.95 & 1.761 & 0.668 & \\
$\mathrm{Mn}$ & 19.19 & 1.682 & 0.595 & 0.987 \\
$\mathrm{~Pb}$ & 2.69 & 0.679 & 1.473 & 0.971 \\
$\mathrm{Zn}$ & 83.56 & 3.011 & 0.332 & 0.975 \\
\hline
\end{tabular}




\subsection{Effect of Temperature}

The effect of temperature on the adsorption of $\mathrm{Cu}^{2+}, \mathrm{Pb}^{2+}$, $\mathrm{Mn}^{2+}$ and $\mathrm{Zn}^{2+}$ from solutions containing modified silica was studied at different temperatures. Table 1 shows that the removal of metal ions from aqueous solution by modified silica is temperature dependent. Increase in temperature from $28^{\circ} \mathrm{C}$ to $43^{\circ} \mathrm{C}$ was found to result in a steady decrease in the removal efficiency of the adsorbent for the metal ions. This is probably due to the effect of temperature on the interaction between the adsorbent surface and the metal ions in solution [13]. $\mathrm{Pb}^{2+}$ was found to have the highest percengage adsorbed of $96.60 \%$ at the temperature of $28^{\circ} \mathrm{C}$ and $\mathrm{Cu}^{2+}$ was the least with percentage removal of $80.89 \%$ at the temperature of $28^{\circ} \mathrm{C}$. The removal efficiency is in the order $\mathrm{Pb}^{2+}>\mathrm{Zn}^{2+}>\mathrm{Mn}^{2+}>\mathrm{Cu}^{2+}$. This implies that the decrease in the adsorption process might be due to the weakening of the attractive forces between the adsorbent and the adsorbate ions. An increase in the temperature between $28^{\circ} \mathrm{C}$ and $43^{\circ} \mathrm{C}$ caused proportional decrease in the amount of metal ion adsorbed onto the surface of the adsorbent. At high temperature, the thickness of the boundary layer was expected to decrease due to the increased tendency of the metal ion to escape from the surface of the adsorbent to the solution phase, hence there was bound to be weak adsorption interaction between the adsorbent and the adsorbate. This decrease in adsorption capacity with increase in temperature indicates that the adsorption processes were exothermic in nature $[15,16]$.

\subsection{Effect of $\mathrm{pH}$}

The effect of $\mathrm{pH}$ on the adsorption of $\mathrm{Pb}, \mathrm{Zn}, \mathrm{Cu}$ and $\mathrm{Mn}$ solution was studied for 8 hours at $28^{\circ} \mathrm{C}$. Table 2 shows that the percentage adsorbed of the metal ions increased as the $\mathrm{pH}$ moves from the acidic $\mathrm{pH}$ to alkaline $\mathrm{pH}$ of 8 and decreased at $\mathrm{pH} 10$. This shows that alkaline medium tend to support adsorption more than acidic medium. However, the low efficiency at $\mathrm{pH} 10$ is attributed to precipitation of metal ions at $\mathrm{pH}$ greater than 8 . The solubility of metals is also known to be lowered at $\mathrm{pH}$ greater than 8 . At low $\mathrm{pH}$ values the surface of the adsorbent would be closely associated with hydroxium ions $\left(\mathrm{H}_{3} \mathrm{O}^{-}\right)$, by repulsive forces, to the surface functional groups, consequently decreasing the percentage adsorption of metal. When the $\mathrm{pH}$ of the adsorbing medium was increased from $\mathrm{pH} 4$ to 10 , there was a corresponding increase in the deprotonation of the adsorbent surface, leading to a decrease in $\mathrm{H}^{+}$ion on the adsorbent surface. This creates more negative charges on the adsorbent surface, which favours adsorption of positively charge species and the positive sites on the adsorbent surface [13]. This corresponds with the effect of $\mathrm{pH}$ on the adsorption of metal ions using coalfly ash as adsorbent [17]. The removal percentage followed the trend $\mathrm{Pb}^{2+}>\mathrm{Cu}^{2+}>\mathrm{Zn}^{2+}>\mathrm{Mn}^{2+}$.

\subsection{Effect of Contact Time}

The effect of agitation time is one of the important factors when considering batch sorption system. This is important since it gives insight into a sorption process, provides information on the minimum time required for considerable adsorption to take place and the possible diffusion control mechanism between the metal ions as it moves from the solution towards the adsorbent surface [18].

Table 3 shows the adsorption of metal ions using modified silica. It is observed that the concentration of metal ions adsorbed on the silica increased with time. The maximum adsorption percentage was $99.20 \%$ and the minimum adsorption percentage was $80.91 \%$. The observed percentage removal trend was $\mathrm{Pb}^{2+}>\mathrm{Zn}^{2+}>\mathrm{Mn}^{2+}>\mathrm{Cu}^{2+}$. The increasse in the adsorption was gradual after some hours which imply that during the initial stage of adsorption, a large number of vacant surface sites were available for adsorption but after lapse of time, the remaining vacant surface sites were occupied with difficulty due to repulsive forces between the solute molecules on the adsorbent surface and the solution phase. This is due to the migration of higher fraction of the metal ions from the solution through the adsorbent boundary layer on the active sites of the adsorbent as time progresses. The initial faster rate may be due to the availability of the uncovered surface area of the adsorbents, since the adsorption kinetics depends on the surface area of the adsorbents. This phenomenon has also been proven by some researchers $[13,19]$.

\subsection{Effect of Adsorbent Dosage}

Adsorbent dosage is an important parameter in the adsorption of metal ions from aqueous solution owing to its effects on the amount of metal ions removed per unit mass of adsorbent [20].

Table 4 shows an increase in adsorption percentage of heavy metal removal as the adsorbed mass increases from 0.5 $\mathrm{g}$ to $2.0 \mathrm{~g}$. The maximum adsorption percentage was found to be $98.93 \%$ and the minimum percentage was $77.67 \%$. It can be inferred that the percentage adsorbed of metal ions increased with increasing mass of modified silica. This is due to the greater availability of the exchangeable sites or surface area at the higher dose of the adsorbent. The observed trend of percentage adsorbed on the metal ion was $\mathrm{Pb}^{2+}>\mathrm{Zn}^{2+}>\mathrm{Mn}^{2+}>\mathrm{Cu}^{2+}$ for the modified silica.. This effect has corresponded with the results of previous studies [21, 22]. The general trend of the adsorption is as shown $\mathrm{Pb}^{2+}>\mathrm{Cu}^{2+}>\mathrm{Zn}^{2+}>\mathrm{Mn}^{2+}$.

\subsection{Isotherm Studies}

The analysis of equilibrium data of metal ions was done using the Langmuir and Freundlich isotherms. The Langmuir equation is given as

$$
\frac{C_{e}}{q_{e}}=\frac{1}{K_{L} q_{\max }}+\frac{1}{q_{\max }} C_{e}
$$

A linearized plot of $\mathrm{C}_{e} / \mathrm{q}_{e}$ against $\mathrm{C}_{e}$ yields a straight line graph which has an intercept and slope which correspond to $\left(1 / \mathrm{k}_{\mathrm{L}} \cdot \mathrm{q}_{\max }\right)$ and $\left(1 / \mathrm{q}_{\max }\right)$, respectively, from which the $\mathrm{q}_{\max }$ and 
$\mathrm{K}_{\mathrm{L}}$ can be calculated.

To confirm the favourability of an adsorption process to Langmuir isotherm, the essential features of the isotherm can be expressed in terms of a dimensionless constant known as the separation factor or equation parameter, $\mathrm{R}_{\mathrm{L}}$, which can be calculated by the following equation.

$$
R_{L}=\frac{1}{\left(1+K_{L} C_{O}\right)}
$$

where,

$\mathrm{C}_{\mathrm{o}}$ is the initial adsorbate concentration.

The value of $R_{L}$ indicates whether the isotherm is irreversible $\left(\mathrm{R}_{\mathrm{L}}=0\right)$, favourable $\left(0<\mathrm{R}_{\mathrm{L}}<1\right)$, linear $\left(\mathrm{R}_{\mathrm{L}}=1\right)$ or unfavourable $\left(\mathrm{R}_{\mathrm{L}}>1\right)$ [23].

The Freundlich equation can be linearized as shown in equation (6)

$$
\log q_{e}=\log k_{F}+\frac{1}{n} \log C
$$

The constants, $\mathrm{k}_{\mathrm{F}}$ and $\mathrm{n}$, are determined by plotting $\log \mathrm{C}$ on the abscissa and $\log \mathrm{q}_{\mathrm{e}}$ on the ordinate. A best fit of the experimental data provides values for $\mathrm{k}_{\mathrm{F}}$ and $\mathrm{n}$ based on the $\mathrm{y}$ intercept and the slope, respectively. The Freundlich equation is useful in cases where the actual identity of the adsorbate is not known [24].

\subsection{Langmuir and Freundlich Adsorption Isotherm Models}

The analysis of equilibrium data for the adsorption of $\mathrm{Cu}^{2+}, \mathrm{Pb}^{2+}, \mathrm{Mn}^{2+}$ and $\mathrm{Zn}^{2+}$ from solutions containing modified silica was investigated using Langmuir and Freundlich adsorption isotherm models as shown in Tables 5 and 6 respectively. The $\mathrm{R}_{\mathrm{L}}$ for $\mathrm{Cu}^{2+}, \mathrm{Pb}^{2+}, \mathrm{Mn}^{2+}$ and $\mathrm{Zn}^{2+}$ ions were found to be $0.262,0.167,0.038$ and 0.062 , respectively. The $R_{L}$ is greater than 0 but less than 1 indicating that the Langmuir isotherm is favourable. The value of $1 / \mathrm{n}$ for $\mathrm{Cu}, \mathrm{Mn}, \mathrm{Pb}$ and $\mathrm{Zn}$ ions were found to be $1.762,1.682,0.679$ and 3.011 respectively which indicates that only $\mathrm{Pb}$ with $1 / \mathrm{n}$ value of 0.679 is favoured [92]. The coefficients of determination $\left(\mathrm{R}^{2}\right)$ for $\mathrm{Cu}$ and $\mathrm{Zn}$ ions were found to be 0.998 and 0.964 respectively for Langmuir and 0.987 and 0.818 for Freundlich which proved that the adsorption data best fitted well in Langmuir isotherm model. For $\mathrm{Mn}$ and $\mathrm{Pb}$, the coefficients of determination $\left(\mathrm{R}^{2}\right)$ were found to be 0.952 and 0.924 for Langmuir and 0.971 and 0.975 for Freundlich which proved that the adsorption data best fitted for Freundlich model. However, Langmuir was said to have the best fit as the $R_{L}$ was favoured for all values and having the highest coefficient of determination $\left(\mathrm{R}^{2}\right)$ of 0.998 . The Langmuir fit is consistent with a strong monolayer adsorption at specific sites on the surface of the modified silica $[25,26]$.

\section{Conclusion}

Production of silica from agricultural by-product has provided an environmentally friendly solution with technically acceptable and economically attractive value added product. Adsorption of Copper, Zinc, Manganese and Lead by silica has been shown to depend significantly on the temperature, $\mathrm{pH}$, contact time and adsorbent dosage. Adsorption by low cost adsorbent and biosorbents is recognized as an effective and economic alternative method for wastewater treatment. The experimental data fitted into Langmuir and Freundlich isotherm models. However, Langmuir isotherm model was found to have the highest coefficient of determination $\left(\mathrm{R}^{2}\right)$ and hence the best fit.

\section{References}

[1] Adam, F., Balakrishnan, S. and Wong, P. (2006). Rice husk ash silica as a support material for ruthenium based heterogeneous catalyst. Journal of Physical Science. 17 (2): $1-13$.

[2] Otaru, A. J., Ameh, C. U., Abdulkareem, A. S., Odigure, J. O. and Okafor, J. O. (2013). Development and characterization of adsorbent from rice husk ash to bleach vegetable oils. Journal of Applied Chemistry. 4: 42-49.

[3] Juliano, B. (1985). An improved rice hull ash concrete admixture. "Rice: Chemistryand Technology" Patent EP0330462A2. $2^{\text {nd }}$ ed.

[4] Gidde, M. R., and Jivani, A. P. (2007). Waste To Wealth Potential of rice husk In India, A literature review, Proceedings of The International Conference On Cleaner Technologies and Environmental Management PEC, Pondicherry, India. 586-590.

[5] Types and application of adsorbents www.marketsandmarkets.com/Market-report. Retrieved 29 January, 2017.

[6] Siswoyo, E. (2014). Development of low-cost adsorbents based on solid waste materials to remove heavy metals ions in water. A Research Thesis submitted to division of Environmtental Science development, Graduate School. Hokkaido University.

[7] Dara, S. S. (2005). Environmental chemistry and pollution control. $8^{\text {th }}$ ed. Ram Nagar, New Dehli, Rajandra Ravindra printers. 342-348.

[8] Dada, O. Ojediran, J. O. and Olalekan, A. P. (2013). Sorption of $\mathrm{Pb}^{2+}$ from aqueous solution unto modified rice husk: Isotherms Studies, Journal of Advances in Physical Chemistry. 6: $1-6$.

[9] Prabha R. T., and Udayashankara, T. H. (2014). Removal of heavy metal from synthetic wastewater using rice husk and groundnut shell as adsorbents, Journal of Environmental Science, Toxicology and Food Technology. 8: 26-34.

[10] Adejo, S. O. and Ekwenchi, M. M. (2014). Proposing a new empirical adsorption isotherm known as Adejo-Ekwenchi isotherm, Journal of Applied Chemistry, 6: 66-71.

[11] Atkins, P. W. (1990). Physical chemistry, $4^{\text {th }}$ edition oxford university press, Tokyo: 884.

[12] Protor, A., Shultz, J. and Kalapathy, U. (2000). A simple method for production of pure Silica from rice hull ash. Journal of Bioresource Technology. 73: 257-264. 
[13] Okafor, P. C., Okon, P. U., Daniel, E. F. and Ebenso, E. E. (2012). Adsorption Capacity of Coconut (Cocos nucifera L.) Shell for Lead, Copper, Cadmium and Arsenic from Aqueous Solutions, International Journal of Electrochemical Scienc., 7: 12354-12369.

[14] Atsar, F. S. (2013) Removal of heaavy metals from spent lubricating oil using modified clay. A dissertation submitted to postgraduate school, in chemistry department, Benue State University, Makurdi.

[15] Vilar, V. J. P., Botelho, C. M. S and Boaventura, R. A. R. (2005) "Influence of $\mathrm{pH}$, ionic Strength and temperature on lead biosorption by gelidium and agar extraction Algal waste, Process Biochem, 40: 3267-3275.

[16] Adedamola, T. O. and Olugbenga, S. B. (2016). Sequestering heavy metals from waste Water using cow dung, Journal of Water Resources and Industry, 13; 1-13.

[17] Bayat, B. (2002). Comparative study of adsorption properties of Turkish fly ash, the case of nickel (II), copper (II) and zinc (II), Journal of Hazardous material, 144: 251-273.

[18] Augustine, A. A., Orike, B. D. and Edidiong, A. D. (2007). Adsorption kinetics and Modelling of $\mathrm{Cu}$ (II) ion sorption from aqueous solution by mercaptoacetic Acid modified cassava wastes, Journal of Environmental, Agricultural and Food chemistry, 6 (9): 309-312.

[19] Wong, J. J. and Sauepra, S. P. (2010). Biosorption of chromium (vi) using rice husk ash modified rice husk ash, Journal of Environmental Research, 4 (3): 244-250.
[20] Olayinka, O. K., Oyedeji, O. A. and Oyeyiola, O. A. (2009). Removal of chromium and Nickel ions from aqueous solution by adsorption on modified coconut husk, African Journal of Environmental Science and Technology, 3 (10): 286-296.

[21] Moyo, M., Muguni, L. and Nyamunda, B. C. (2012). Optimization of copper and zinc Ions removal from aqueous solution by coal fly ash as an adsorbent, International Journal of Science and Technology, 4 (4): 1760-1765.

[22] Handojo, D, U and Mohd, R. S., (2007). Adsorption of Heavy Metals from Water and Wastewater Using Low Cost Adsorbents from Agricultural By-Products, Asian Journal of water, environment and pollution, 6 (2): 73-80.

[23] Kadirvelu, K and Namasivayam, C, (2003). Activated carbon from coconut coir pith as metal adsorbent: adsorption of $\mathrm{Cd}^{2+}$ from aqueous solution. Advances in Environmental Research, 7: 471-478.

[24] Hill, T. L. (1952). Theory of physical adsorption, Advances in Catalysis, 4: 211-258.

[25] Dada, A. O., Olalekan, A. P. and Olatunya, A. M. (2012). Langmuir, Freundlich, Temkin and Dubinin-Radushkevich isotherms studies of equilibrium sorption of $\mathrm{Zn}$ unto phosphonic acid modified rice husk, Journal of applied chemistry, 3: 38-45.

[26] Ahmed, M. S., Hanan, M. E. and Labata, F. T. (2016). Removal of $\mathrm{Pb}$ (II) ions from Aqueous solutions by sulphoric acid treated palm tree leaves. Journal of Taiwan Institute of Chemical Engineers, 58: 264-273. 